\title{
Numerical analysis of the turbulent heat transfer at 2D in a solar chimney
}

 \\ Energy Physics Laboratory, Department of Physics, University Mentouri Constantine, Algeria
}

\begin{abstract}
The main objective of this work is to make the numerical analysis of velocity fields and temperature (heat transfer) in a solar chimney with different numbers of Rayleigh. The problem is to study natural turbulent convection in a tow dimensionless system, with well-defined boundary conditions. The results obtained, for the different studied cases, are compared to show the influence of various parameters. Particular attention is paid to the velocity profiles and to horizontal and vertical temperature inside the chimney. The Fluent software was used.
\end{abstract}

Keywords: Solar chimney, heat transfer, numerical simulation

\section{Introduction}

In some areas where solar energy is widely available but the wind power is weak and / or unstable, the current study shows the potential to generate air movement in the form of artificial wind starting from solar energy. This airflow is used to drive one or more wind turbines. The combination of these two types of energy is through a device called the solar chimney. The solar chimney is a generator of electrical power from solar energy. It was originally proposed by Professor J. Schlaich Stuttgartin 1968 [1] And it consists of three main components [2]: the solar collector or the greenhouse, the chimney or tower, and the wind turbine.

\subsection{Nomenclature}

$\alpha:$ Thermal diffusivity $\mathrm{m}^{2} / \mathrm{s}$

$\beta$ : Coefficient of thermal expansion $1 / \mathrm{K}$

$\mu$ : Dynamic viscosity $\mathrm{Kg} / \mathrm{m}$. $\mathrm{s}$

$v:$ Kinematic viscositym ${ }^{2} / \mathrm{s}$

$\lambda$ : Thermal conductivity $\mathrm{W} / \mathrm{m} . \mathrm{K}$

$\rho$ : Density $\mathrm{Kg} / \mathrm{m}^{3}$

$c_{P}:$ specific heat J/ Kg.K

$g:$ Acceleration of gravity $\mathrm{m} / \mathrm{s}^{2}$

$H_{c}$ : Chimney Height $\mathrm{m}$

$P_{r}:$ Prandtl number
$H$ : Height of collector $\mathrm{m}$

$P$ : Pressure $\mathrm{Pa}$

$p^{*}$ : Dimensionless pressure

$T$ : Temperature $\mathrm{K}$

$T^{*}$ : Dimensionless temperature

$u$ : Component velocity in the direction ( $\mathrm{r}$ ) $\mathrm{m} / \mathrm{s}$

$u^{*}$ : Dimensionless velocity component in the (r)

$v$ : Component velocity in the direction $(\mathrm{z}) \mathrm{m} / \mathrm{s}$

$v^{*}$ : Dimensionless velocity component in the (z)

* Manuscript received July 10, 2015; revised September 26, 2015.

Corresponding author. Tel.: +0-213-3184-1559; E-mail address: djsamir.25@gmail.com.

doi: $10.12720 /$ sgce.4.4.305-310 


\section{Mathematical Model and Boundary Conditions}

We consider that the geometry of the solar chimney consists of two cylindrical cavities which are open and superimposed on each other (the chimney and collectors). The geometry and dimensions of this system are illustrated in Fig. 1. The characteristics of the rotational symmetry of the cylinder makes the solution two-dimensional (depends only on $\mathrm{r}$ and $\mathrm{z}$ ). Then, the geometry of the solar chimney is as shown in Fig. 2.

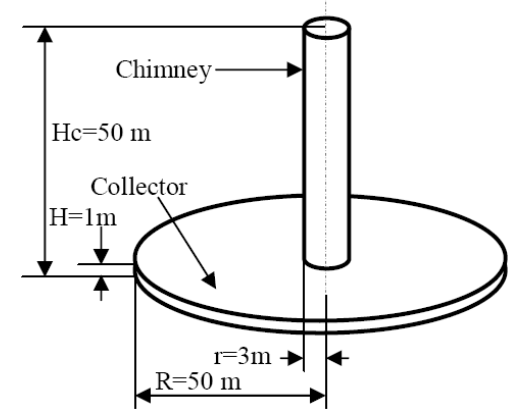

Fig. 1. Solar chimney dimensions.

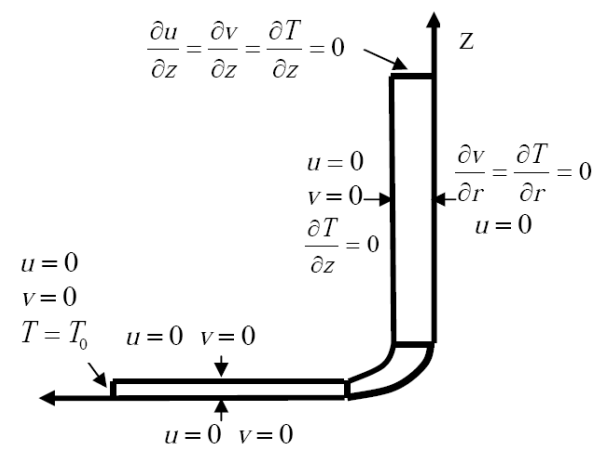

Fig. 2. Two-dimensional geometric of the solar chimney with boundary conditions

The flow of incompressible Newtonian fluid in the stationary two-dimensional case is governed by the basic equations which are: continuity equation, Navier-Stokes and energy equation [3]-[5].

The used dimensionless variables are:

$$
u^{*}=\frac{u}{U_{0}}=u \frac{H}{\alpha}, v^{*}=\frac{v}{U_{0}}=v \frac{H}{\alpha}, p^{*}=\frac{p}{P_{0}}=\frac{P}{\rho U_{0}^{2}}, T^{*}=\frac{T-T_{0}}{T_{1}-T_{0}}, r^{*}=\frac{r}{H}
$$

Continuity equation:

$$
\frac{u^{*}}{r^{*}}+\frac{\partial u^{*}}{\partial r^{*}}+\frac{\partial v^{*}}{\partial z^{*}}=0
$$

Linear r-momentum conservation:

$$
u^{*} \frac{\partial u^{*}}{\partial r^{*}}+v^{*} \frac{\partial u^{*}}{\partial z^{*}}=-\frac{\partial P^{*}}{\partial r^{*}}+\operatorname{Pr}\left(\frac{u^{*}}{r^{* 2}}+\nabla^{2} u^{*}\right)
$$

Linear z-momentum conservation: 
$u^{*} \frac{\partial v^{*}}{\partial r^{*}}+v^{*} \frac{\partial v^{*}}{\partial z^{*}}=-\frac{\partial P^{*}}{\partial z^{*}}+\operatorname{Pr}\left(\nabla^{2} v^{*}\right)+R a \cdot \operatorname{Pr} T^{*}$

Energy equation:

$u^{*} \frac{\partial T^{*}}{\partial r^{*}}+v^{*} \frac{\partial T^{*}}{\partial z^{*}}=\nabla^{2} T^{*}$

The Rayleigh number and Prandtl characterizing the problem are expressed by the equations:

$$
R a=\frac{g \beta \Delta \mathrm{TH}^{3}}{\alpha v}, \operatorname{Pr}=\frac{v}{\alpha}
$$

The utilized turbulence model is $k-\varepsilon$. The equation of turbulent kinetic energy is:

$$
\frac{\partial k}{\partial t}+\bar{u}_{k} \frac{\partial k}{\partial x_{k}}=\frac{\partial}{\partial x_{k}}\left[\left(v+\frac{C_{u} k^{2}}{\sigma_{k} \varepsilon}\right) \frac{\partial k}{\partial x_{k}}\right]+\frac{C_{u} k^{2}}{\varepsilon}\left(\frac{\partial \bar{u} i}{\partial x_{k}}+\frac{\partial \bar{u}_{k}}{\partial x_{i}}\right) \frac{\partial \bar{u}_{i}}{\partial x_{k}}-\varepsilon
$$

The equation for the dissipation of turbulent kinetic energy is:

$$
\frac{\partial \varepsilon}{\partial t}+\bar{u}_{k} \frac{\partial \varepsilon}{\partial x_{k}}=\frac{\partial}{\partial x_{k}}\left(v+\frac{C_{u} k^{2}}{\sigma_{e} \varepsilon}\right) \frac{\partial \varepsilon}{\partial x_{k}}+C_{\varepsilon 1} C_{u} k\left(\frac{\partial \bar{u}_{i}}{\partial x_{k}}+\frac{\partial \bar{u}_{k}}{\partial x_{i}}\right) \frac{\partial \bar{u}_{i}}{\partial x_{k}}-C_{\varepsilon 2} \frac{\varepsilon^{2}}{k}
$$

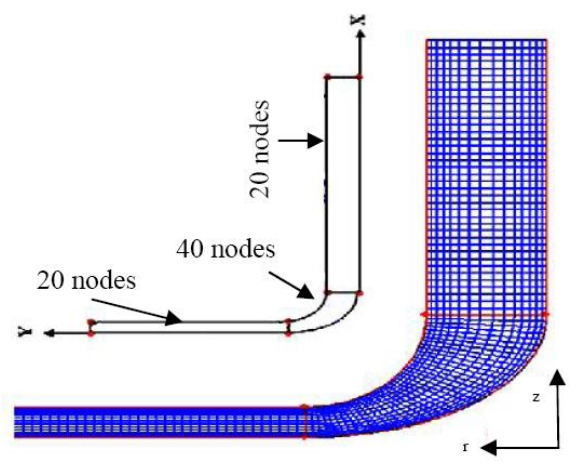

Fig. 3. Mesh geometry.

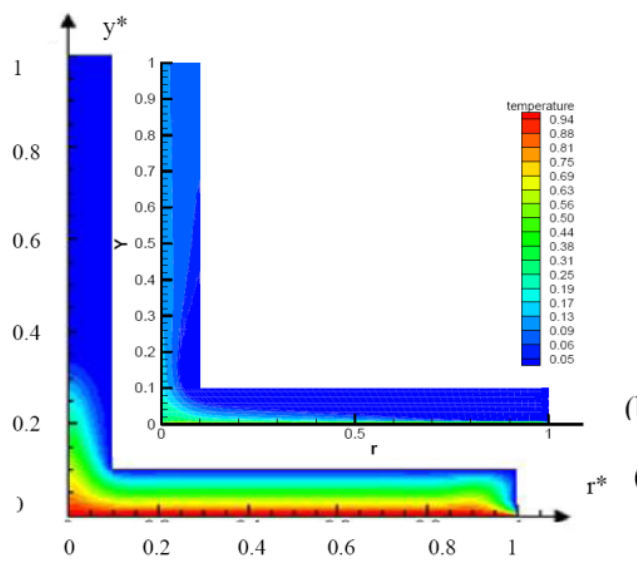

Fig. 4. Comparison of dimensionless isothermal lines: (a) toufik chergui and al [6], (b) our results . 
As shown in Fig. 3, double rations have been used, for the mesh, to refine much area calculation. As for the energy equation, the convergence criterion is $10^{-6}$, and $10^{-3}$ for the other equations. To validate our simulations, our results have been compared with those of Toufik Chergui and al [6] Fig. 4.

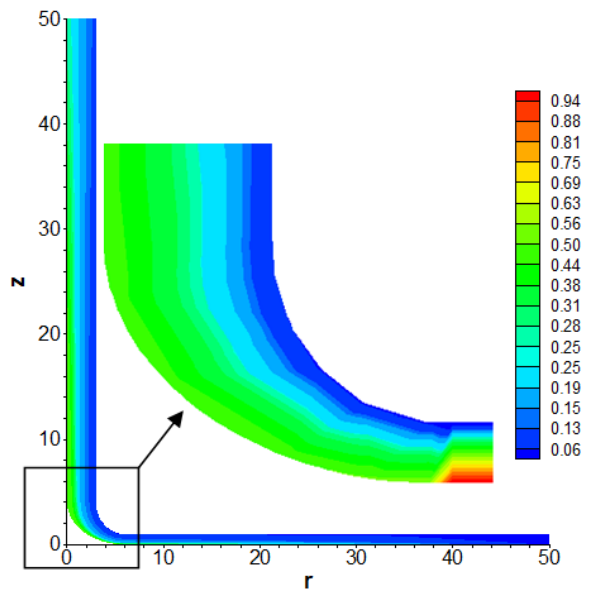

Fig. 5. Dimensionless isothermal lines for: $\mathrm{Ra}=1.14 * 10^{9}$.

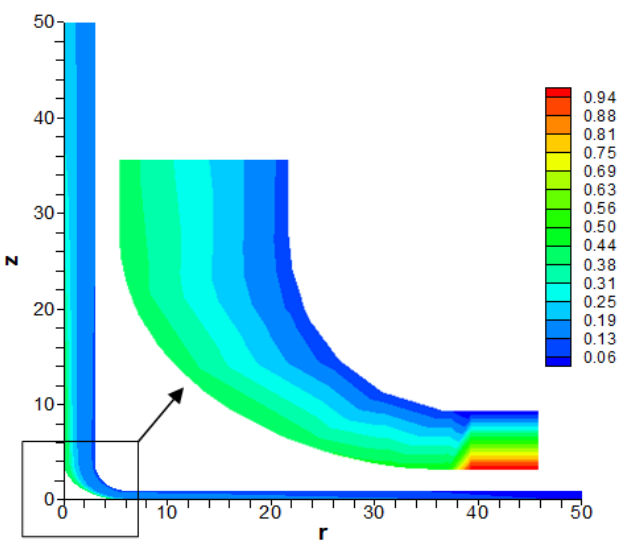

Fig. 6. Dimensionless isothermal lines for: $\mathrm{Ra}=3.42 * 10^{9}$.

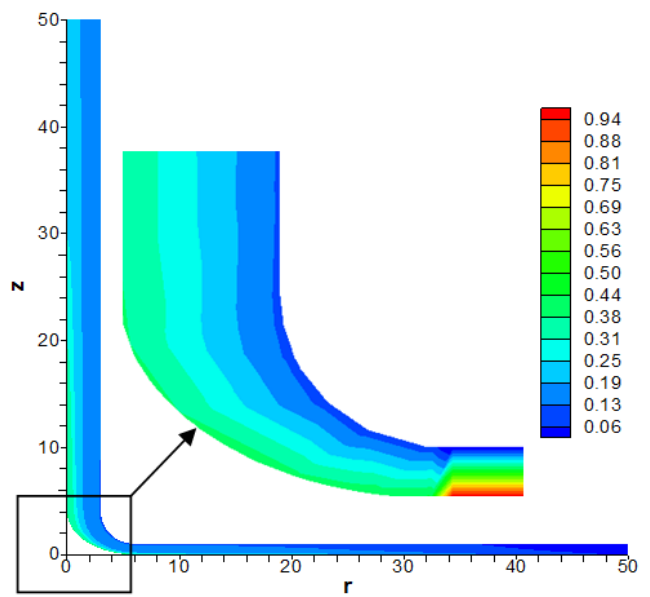

Fig. 7. Dimensionless isothermal lines for: $\mathrm{Ra}=7.98 * 10^{9}$. 


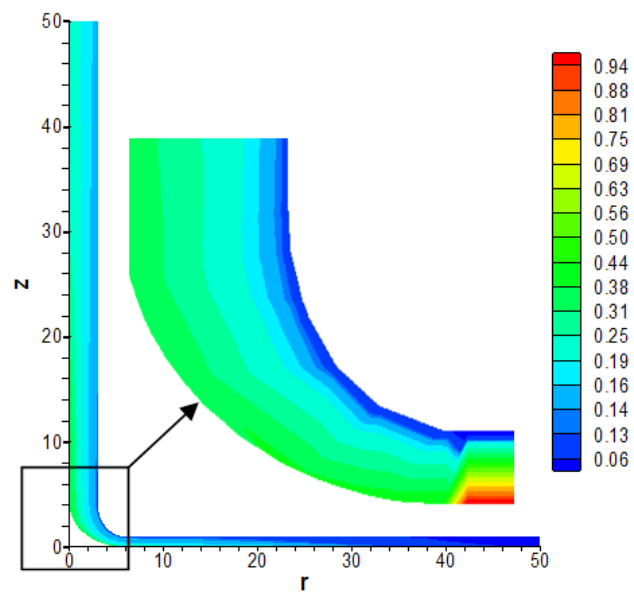

Fig. 8. Dimensionless isothermal lines for: $\mathrm{Ra}=1.03 * 10^{10}$.

\section{Results and Discussion}

In the case of natural convection, the dimensionless equations show that the Prandtl numbers and the Rayleigh control the flow. [7] Thus, to study this transfer mode, simply change the Rayleigh number.

The present study focuses on air flow $(\mathrm{Pr}=0.71)$ for turbulent flow [6] Fig. 5, Fig. 6, Fig. 7 and Fig. 8 show the dimensionless isothermal lines for Rayleigh numbers equal to $1.14 * 10^{9}, 3.42 * 10^{9}, 7.98 * 10^{9}$ and $1.03 * 10^{10}$ respectively. The maximum temperature is located near the ground in the collector due to heat transfer exchange between this surface and the airflow beneath the cover. Notice that the temperature increases with Rayleigh numbers Fig. 9 [7], [8].

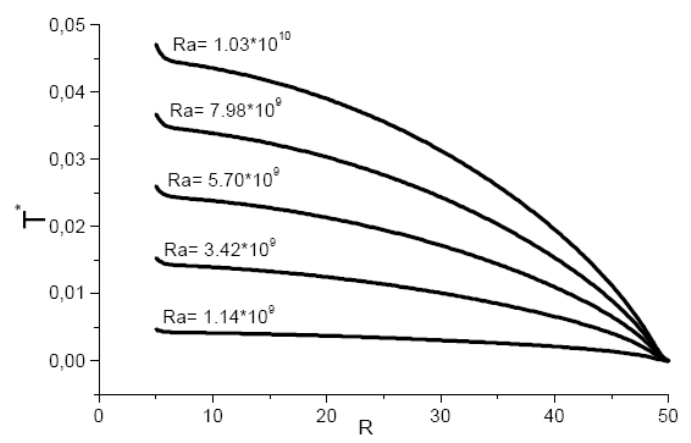

Fig. 9. Temperature profiles at $\mathrm{Z}=0.5$ of collector radius for different numbers of Ra.

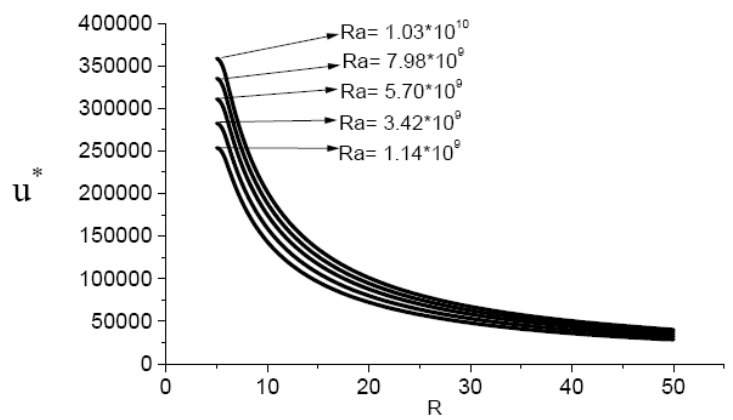

Fig. 10. Velocity profiles at $Z=0.5$ of collector radius for different numbers of $\mathrm{Ra}$.

Fig. 9 and Fig. 10 show the profiles of temperature and velocity at mid-height of the collectors $(\mathrm{z}=0.5)$ 
for different Rayleigh numbers. The velocity profiles obtained at $\mathrm{z}=0.5$ show that the rate increases gradually heading towards the interior of the chimney exponentially. This increase is due to the conservation of mass and shape of the collector (inlet and outlet of the same section). [7]-[8]

\section{Conclusion}

The numerical simulation of solar chimney power plant system has been carried out to give a reference for the design of large-scale solar chimney power plant systems; in this paper we have presented a numerical simulation for the solar chimney power plant system in turbulent regime to show the influence of Rayleigh number on temperature fields and velocity. This study considers the heat transfer process and the fluid flow in the collector and the chimney under some imposed operational conditions. The results show that the performance are related to geometrical and operating parameters, the velocity increases as it moves toward the center of the chimney in an exponential manner. Furthermore, it is unambiguous that the flow rate increases as the Rayleigh becomes greater. These results helped us to choose the optimal location of the turbine in solar chimney to generate more energy and estimate the performance in terms of solar radiation depending on the number of Rayleigh.

\section{References}

[1] Trieb F, Langni $\beta$ O, Klai $\beta$ H. Solar electricity generation-a comparative view of technologies, costs and environmental impact. Solar energy, 1997; 59(1):89-99.

[2] Schlaich J. The Solar Chimney: Electricity from the Sun. Edition Axel Menges; 1995.

[3] Documentation FLUENT, Fluent Inc; 1998.

[4] Patankar S. Numerical heat Transfer and Fluid Flow. CRC Press; 1980.

[5] Djimli S, Chaker A. Numerical study of the solar chimney power plant performance in the region of M'Sila-Algeria. Power (W), 2014:1-2.

[6] Chergui T, Larbi S, Bouhdjar A. Thermo-hydrodynamic aspect analysis of flows in solar chimney power plants - A case study. Renewable and Sustainable Energy Reviews, 2010; 14(5):1410-1418.

[7] dos Santos Bernardes MA, Valle RM, Cortez MFB. Numerical analysis of natural laminar convection in a radial solar heater. International Journalof Thermal Sciences, 1999; 38(1):42-50.

[8] Beyers JHM, Harms TM, Kröger DG. A finite volume analysis of turbulent convective heat transfer for accelerating radial flows. Numerical Heat Transfer: Part A: Applications, 2001; 40(2):117-138. 